\title{
Interhemispheric transport of metallic ions within ionospheric sporadic $E$ layers by the lower thermospheric meridional circulation
}

\author{
Bingkun Yu${ }^{1,2}$, Xianghui Xue ${ }^{1,3,4,5}$, Christopher J. Scott ${ }^{2}$, Jianfei Wu ${ }^{1,3,4}$, Xinan Yue ${ }^{6}$, Wuhu Feng ${ }^{7,8}$, Yutian Chi ${ }^{1,2}$, \\ Daniel R. Marsh ${ }^{7,9}$, Hanli Liu ${ }^{10}$, Xiankang Dou ${ }^{1,5,11}$, and John M. C. Plane \\ ${ }^{1}$ CAS Key Laboratory of Geospace Environment, Department of Geophysics and Planetary Sciences, \\ University of Science and Technology of China, Hefei, China \\ ${ }^{2}$ Department of Meteorology, University of Reading, Berkshire, UK \\ ${ }^{3}$ CAS Center for Excellence in Comparative Planetology, Hefei, China \\ ${ }^{4}$ Anhui Mengcheng Geophysics National Observation and Research Station, University of Science and \\ Technology of China, Hefei, China \\ ${ }^{5}$ Hefei National Laboratory for the Physical Sciences at the Microscale, University of Science and \\ Technology of China, Hefei, China \\ ${ }^{6}$ Key Laboratory of Earth and Planetary Physics, Institute of Geology and Geophysics, \\ Chinese Academy of Sciences, Beijing, China \\ ${ }^{7}$ School of Chemistry, University of Leeds, Leeds, UK \\ ${ }^{8}$ National Center for Atmospheric Science, University of Leeds, Leeds, UK \\ ${ }^{9}$ National Center for Atmospheric Research, Boulder, CO, USA \\ ${ }^{10}$ High Altitude Observatory, National Center for Atmospheric Research, Boulder, CO, USA \\ ${ }^{11}$ Electronic Information School, Wuhan University, Wuhan, China
}

Correspondence: Xianghui Xue (xuexh@ustc.edu.cn) and Christopher J. Scott (chris.scott@reading.ac.uk)

Received: 4 August 2020 - Discussion started: 2 October 2020

Revised: 27 January 2021 - Accepted: 9 February 2021 - Published: 18 March 2021

\begin{abstract}
Long-lived metallic ions in the Earth's atmosphere (ionosphere) have been investigated for many decades. Although the seasonal variation in ionospheric "sporadic $E$ " layers was first observed in the 1960s, the mechanism driving the variation remains a long-standing mystery. Here, we report a study of ionospheric irregularities using scintillation data from COSMIC satellites and identify a large-scale horizontal transport of long-lived metallic ions, combining the simulations of the Whole Atmosphere Community Climate Model with the chemistry of metals and ground-based observations from two meridional chains of stations from 19752016. We find that the lower thermospheric meridional circulation influences the meridional transport and seasonal variations of metallic ions within sporadic $E$ layers. The winterto-summer meridional velocity of ions is estimated to vary between -1.08 and $7.45 \mathrm{~m} / \mathrm{s}$ at altitudes of $107-118 \mathrm{~km}$ between $10-60^{\circ} \mathrm{N}$. Our results not only provide strong support for the lower thermospheric meridional circulation predicted
\end{abstract}

by a whole atmosphere chemistry-climate model, but also emphasize the influences of this winter-to-summer circulation on the large-scale interhemispheric transport of composition in the thermosphere-ionosphere.

\section{Introduction}

Sporadic $E\left(E_{\mathrm{S}}\right)$ layers of metallic ion plasma occur in the $E$ region at altitudes between 90 and $130 \mathrm{~km}$. Unlike other ionospheric layers, formed by the photoionization of $\mathrm{N}_{2}$ and $\mathrm{O}_{2}$, in which the major molecular ions $\mathrm{NO}^{+}$and $\mathrm{O}_{2}^{+}$have lifetimes on the order of seconds, the $E_{\mathrm{S}}$ layer is composed of long-lived (up to $10 \mathrm{~d}$ ) metallic ions (Plane et al., 2015) and is remarkably thin, typically $1-3 \mathrm{~km}$ thick (Layzer, 1972). Over one-third of the interruptions to the Global Positioning System (GPS) and Global Navigation Satellite System (GNSS) caused by ionospheric weather can be attributed to 
the $E_{\mathrm{s}}$ layer (Yue et al., 2016). One long-standing mystery is the marked seasonal variability of $E_{\mathrm{s}}$, with a maximum between $10-60^{\circ}$ latitude in the summer hemisphere and a minimum between $60-70^{\circ}$ latitude in the winter hemisphere (Whitehead, 1989; Tsai et al., 2018; Yu et al., 2019b). The most likely explanation for the seasonal dependence of $E_{\mathrm{s}}$ layers is the wind shear, by which the seasonal variations of zonal and meridional winds in the $E$ region above $95 \mathrm{~km}$ cause the summer $E$ region to be dominated by the vertical convergence of ions but dominated by the diffusion of ions in winter (Yuan et al., 2014). Model-simulated mean divergences of the concentration flux of metallic ions by vertical wind shear are mainly distributed in the mid-latitudes of 20 $40^{\circ}$ in winter (Wu et al., 2005; Chu et al., 2014; Yu et al., $2019 \mathrm{~b}, 2020$ ). A fundamental disagreement of the distribution of the $E_{\mathrm{S}}$ winter minimum exists between observations and recent model simulation, particularly when the effects of magnetic declination angle were considered (Yu et al., $2019 b$ ). Although $E_{\mathrm{s}}$ layers have been investigated since the early years of ionospheric investigations (Whitehead, 1960), their seasonal dependence cannot be explained by the vertical wind shear theory (Whitehead, 1989). This remains one of the weakest points in understanding $E_{\mathrm{S}}$ layer formation. Recently, sporadic $E$-like phenomena were discovered in the Martian ionosphere (Collinson et al., 2020), which indicates that understanding $E_{\mathrm{s}}$ layers and the dynamical and electrodynamical processes that perturb planetary ionospheres is very important for long-distance radio communication on Earth, Mars, and other planets.

Numerical studies indicate that there is a winter-tosummer meridional circulation in the lower thermosphere driven by gravity-wave forcing. This meridional circulation is referred to as the lower thermospheric residual mean meridional circulation (Liu, 2007). Recent modelling studies (Smith et al., 2011; Qian et al., 2017; Qian and Yue, 2017) have found clear signatures that the residual meridional circulation is important for trace gas distributions and composition variations in the thermosphere and ionosphere. However, the lower thermospheric meridional wind is considerably smaller than the amplitudes of tides (Wu et al., 2008), and thus it is difficult to directly measure and characterize.

The present paper reports a study of the global-scale winter-to-summer transport of metallic ions in the upper atmosphere from scintillation data observed by the Constellation Observing System for Meteorology, Ionosphere, and Climate (COSMIC) satellites (Anthes et al., 2008). The wind shear theory is the most likely candidate for explaining the interhemispheric transport of metallic ions within $E_{\mathrm{S}}$ layers. We extend the vertical wind shear theory (Mathews, 1998) to three dimensions, deriving the zonal, meridional, and vertical ion velocities. The large-scale horizontal transport of ions is analysed with respect to the mechanism of $E_{\mathrm{S}}$ formation and a possible impact of the winter-to-summer lower thermospheric circulation on the morphology of $E_{\mathrm{s}}$ layers. The velocity of the meridional transport of metallic ions is quantita- tively estimated from two meridional chains of ground-based ionospheric monitoring stations, located roughly along the Greenwich meridian $\left(0^{\circ} \mathrm{E}\right)$ and $120^{\circ} \mathrm{E}$. These ionospheric observations cover a period of 35 years. The quantitative assessment is consistent with the meridional ion velocity predicted by model calculations.

\section{Results}

It is widely accepted that vertical wind shears in zonal and meridional neutral winds drive the vertical motion of metallic ions in the $E$ region of the ionosphere. To better understand the meridional motion of metallic ions, the contributions to meridional and vertical ion drift from zonal $(U)$, meridional $(V)$, and vertical $(W)$ winds calculated from threedimensional wind shear theory (Eqs. A3-A5) are shown in Fig. 1. It shows that $V$ is the main contributor to the meridional velocity of ions. The meridional wind plays a more important role than the zonal and vertical winds in meridional ion drifts.

The amplitude scintillation S4 index is one of the most important parameters in the GPS and GNSS radio occultation data, defined as the standard deviation of the normalized intensity in signals. Large S4 values indicate ionospheric plasma irregularities with strong fluctuations (Yue et al., 2015; Tsai et al., 2018), which are related to the plasma frequencies of $E_{\mathrm{S}}$ layers (Arras and Wickert, 2018; Resende Chagas et al., 2018). The $E_{\mathrm{S}}$ layer is a thin layer of enhanced plasma irregularities and is composed of metallic ions which converge vertically mainly due to wind shear (Kopp, 1997; Mathews, 1998; Grebowsky and Aiken, 2002). The $E_{\mathrm{s}}$ layer scatters, refracts, or reflects incident $\mathrm{HF}$ and VHF radio waves (Whitehead, 1989). It has been demonstrated that there is a universal connection between S4max occurring at heights of $90-130 \mathrm{~km}$ and critical frequencies of $E_{\mathrm{S}}$ layers (Yu et al., 2020, 2021a). The S4max occurring at $E_{\mathrm{S}}$ altitudes of $90-130 \mathrm{~km}$ is used as a proxy for the electron concentration within $E_{\mathrm{S}}$ layers (Wu et al., 2005; Yue et al., 2015; Arras and Wickert, 2018; Resende Chagas et al., 2018; Yu et al., 2019b, 2021a).

The maps in Fig. $2 \mathrm{a}$ and $\mathrm{b}$ show the geographical distribution of $E_{\mathrm{S}}$ layers represented by the S4max index for winter (December, January, February) and summer (June, July, August) based on the 6-year COSMIC multi-satellite dataset between 2006 and 2011. The most dramatic feature of the global $E_{\mathrm{s}}$ map is the pronounced summer maximum in a broad band of $10-60^{\circ} . E_{\mathrm{S}}$ layers are weaker in winter. The winter minimum of $E_{\mathrm{S}}(\mathrm{S} 4 \mathrm{max}<0.3)$ is observed along the $60-80^{\circ}$ geomagnetic latitude band, dividing the mid-latitude region and polar region. This typical $E_{\mathrm{S}}$ seasonal dependence has been revealed in both hemispheres over the past few decades from ground-based ionosonde, radar, and satellite measurements (Whitehead, 1989; Mathews, 1998; Wu et al., 

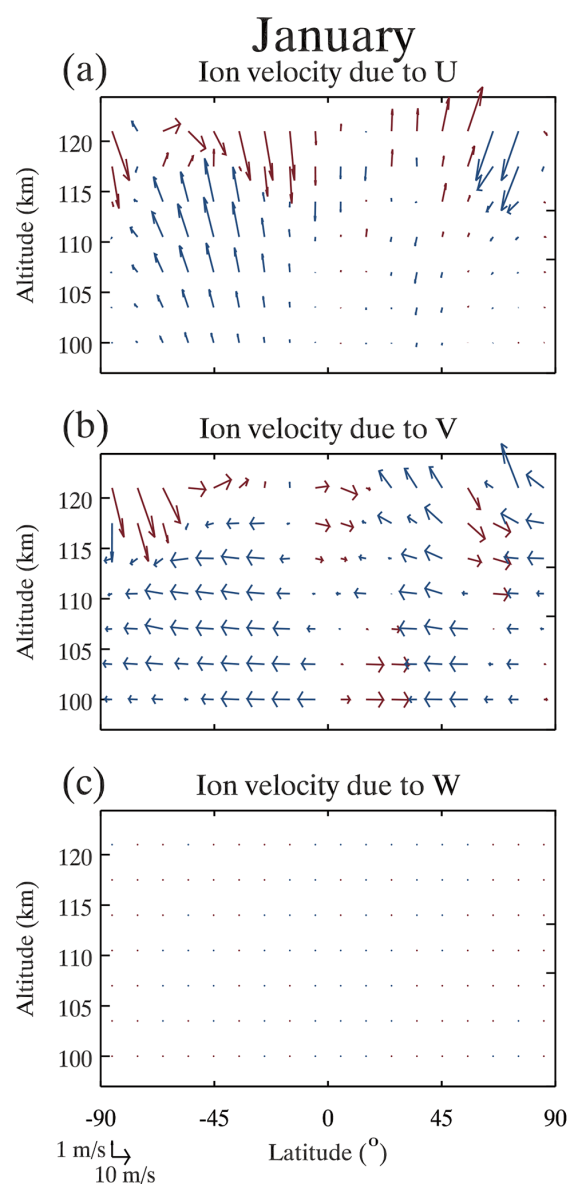

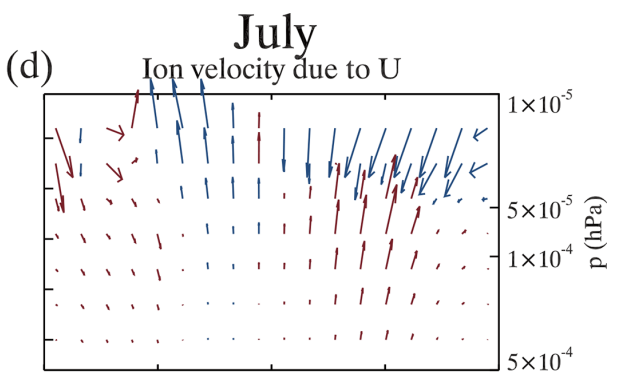

(e)
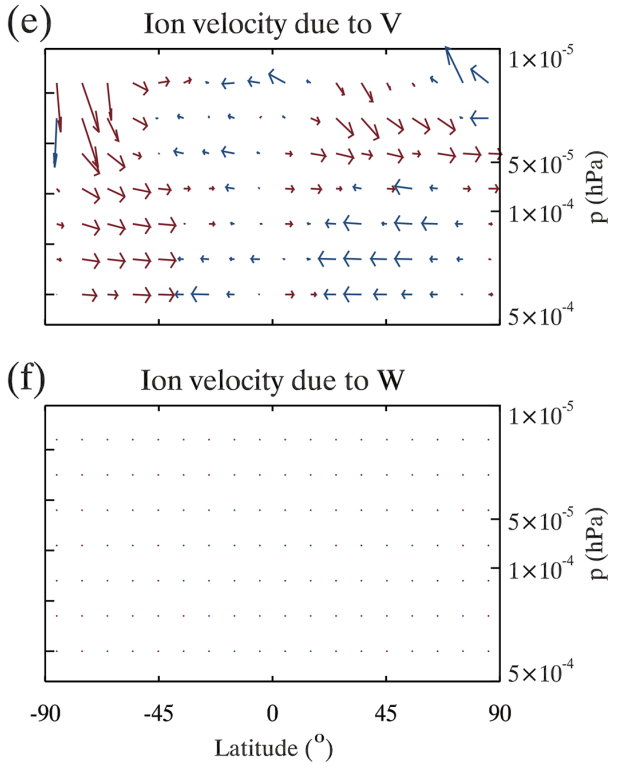

Figure 1. Ion velocity due to zonal $(U)$, meridional $(V)$, and vertical $(W)$ wind in January $(\mathbf{a}-\mathbf{c})$ and July (d-f). The red arrows denote the northward ion drifts, and the blue arrows denote the southward ion drifts (vertical and meridional vectors with scale $1 \mathrm{~m} \cdot \mathrm{s}^{-1} / 10 \mathrm{~m} \cdot \mathrm{s}^{-1}$ ).

2005; Haldoupis et al., 2007; Arras et al., 2008; Chu et al., 2014; Yu et al., 2019b, 2020).

Figure $2 \mathrm{c}$ and $\mathrm{d}$ show the atmospheric circulation in winter and summer averaged from 2006-2011, which has been calculated using SD-WACCM4. Three circulation cells are apparent, which are consistent with previous studies (Qian et al., 2017; Qian and Yue, 2017). Below 95 km, the summer-to-winter mesospheric circulation is driven by gravity-wave forcing. Between $\sim 95$ and $\sim 115 \mathrm{~km}$, the winter-to-summer lower thermospheric circulation is driven by gravity-wave forcing that is in the opposite direction to that which drives the mesospheric circulation. Above $115 \mathrm{~km}$, the thermospheric circulation is a summer-to-winter circulation driven by solar extreme ultraviolet (EUV) heating.

Figure 3 shows the monthly mean variations in the intensity of $E_{\mathrm{S}}$ layers represented by the $\mathrm{S} 4 \mathrm{max}$ index from COSMIC, with superposed ion drifts from the model. The observations of $E_{\mathrm{s}}$ layers from satellites suggest that the maximum $E_{\mathrm{S}}$ latitude has an interhemispheric migration to the summer hemisphere. These $E_{\mathrm{s}}$ seasonal variations have been known for over 50 years (Smith, 1968), but the cause is un- known (Whitehead, 1989; Yu et al., 2019b). The plot also shows a north-south asymmetry (the northern summer peak is stronger than the southern summer peak). The solid green lines are the ratios of column densities of $E_{\mathrm{S}}$ intensities at different latitudes to the global mean column density. Vertical wind shear alone does not account for the variations in relative column densities in $E_{\mathrm{s}}$ layers. The column density of $E_{\mathrm{s}}$ layers should not vary much from month to month if the $E_{\mathrm{s}}$ seasonal dependence is just a result of seasonal variations in vertical wind shears that favour ion convergences in different areas. The peak of the relative column densities shows an interhemispheric transport. This seasonal dependence is consistent with interhemispheric transport of longlived metallic ions by the winter-to-summer lower thermospheric meridional circulation. The yellow arrows between 100 and $120 \mathrm{~km}$ show the predicted meridional and vertical velocity of ion drift from three-dimensional wind shear theory (Eq. A4 and A5) driven by the atmospheric meridional circulations. Above $100 \mathrm{~km}$, metallic ions have a lifetime of at least several days in the thermosphere (Plane et al., 2015). At altitudes of $90-100 \mathrm{~km}$, the lifetime of ions rapidly decrease to timescales of hours to minutes because the ions 

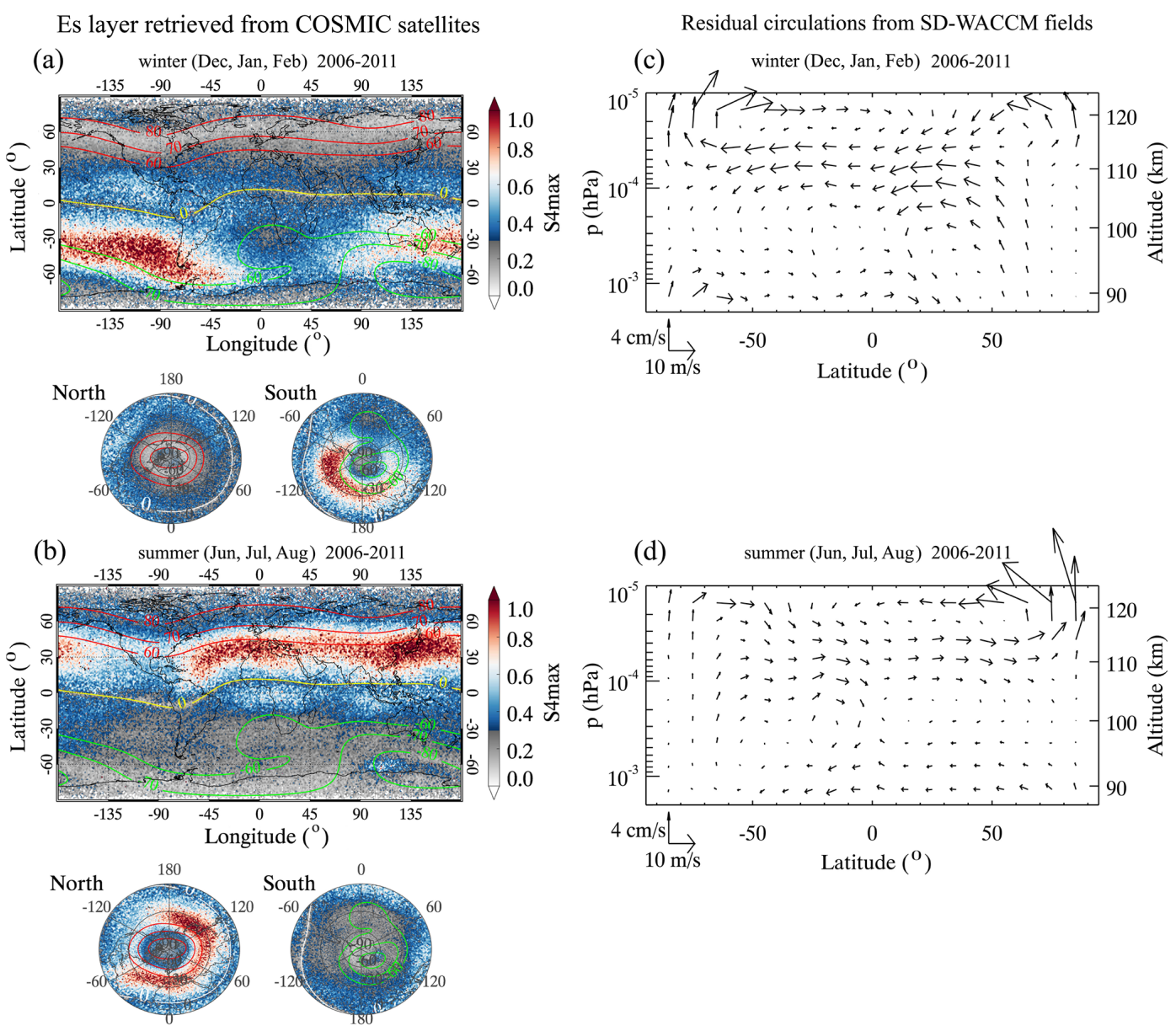

Figure 2. Global distributions of the mean $E_{\mathrm{S}}$ layer intensity represented by the S4max index from COSMIC are shown in (a) and (b) for the winter (December, January, February) and summer (June, July, August), respectively, between 2006 and 2011, detected from COSMIC multi-satellites with a resolution of a $1^{\circ} \times 1^{\circ}$. The red and green curves represent the geomagnetic latitude contours of 60,70 , and $80^{\circ}$ in the Northern Hemisphere and Southern Hemisphere, and the yellow curve represents the geomagnetic Equator. The mean residual circulations are calculated for winter (c) and summer (d) using the SD-WACCM4 (2006-2011). There are three circulation cells: mesospheric circulation, lower thermospheric circulation, and thermospheric circulation. Below $95 \mathrm{~km}$, the summer-to-winter mesospheric circulation is driven by gravity-wave forcing. Between 95 and $115 \mathrm{~km}$, the winter-to-summer lower thermospheric circulation is driven by gravity-wave forcing that is in the opposite direction to that which drives the mesospheric circulation. Above $115 \mathrm{~km}$, the solar-driven thermospheric circulation is a summer-to-winter circulation.

are able to form molecular ions (principally metal oxide ions through reaction with $\mathrm{O}_{3}$ ). Therefore, the predicted velocity of metallic ions is calculated only above $100 \mathrm{~km}$.

It is found that the observed $E_{\mathrm{s}}$ seasonal variation correlates strongly with the ion meridional transport caused by the winter-to-summer lower thermospheric circulation. From February to April, the $E_{\mathrm{S}}$ moves from both hemispheres toward the Equator with a large equatorward ion drift speed over $10 \mathrm{~m} / \mathrm{s}$. Following this, $E_{\mathrm{s}}$ moves northward from May to July and reaches a strong summer maximum in accordance with the wind shear in the lower thermospheric circulation that predicts the winter-to-summer interhemispheric transport of ions. From August to January, $E_{\mathrm{s}}$ migrates toward the Equator with the equatorward metallic ion velocity, followed by a subsequent summer peak in the Southern Hemi- sphere with a southward ion velocity. Further evidence for a link between the seasonal variation and ion meridional transport is a distinctive northern high-latitude depression of $E_{\mathrm{s}}$, which is not well explained by the vertical wind shear effects in previous experimental and theoretical studies (Arras et al., 2008; Chu et al., 2014; Yu et al., 2019b). The dissipative region of $E_{\mathrm{S}}$ during winter solstice agrees with the location at which the mean meridional wind splits between 60 and $70^{\circ} \mathrm{N}$ (Fig. 2c). According to multi-satellite observations and simulation results, the seasonal variation in $E_{\mathrm{s}}$ could be highly dependent on the meridional transport of metallic ions, which is inseparable from the ion dynamics of $E_{\mathrm{s}}$ formation with wind shear effects.

In addition to neutral winds, the electric field also plays an important role in the transport of metallic ions (Nygren 


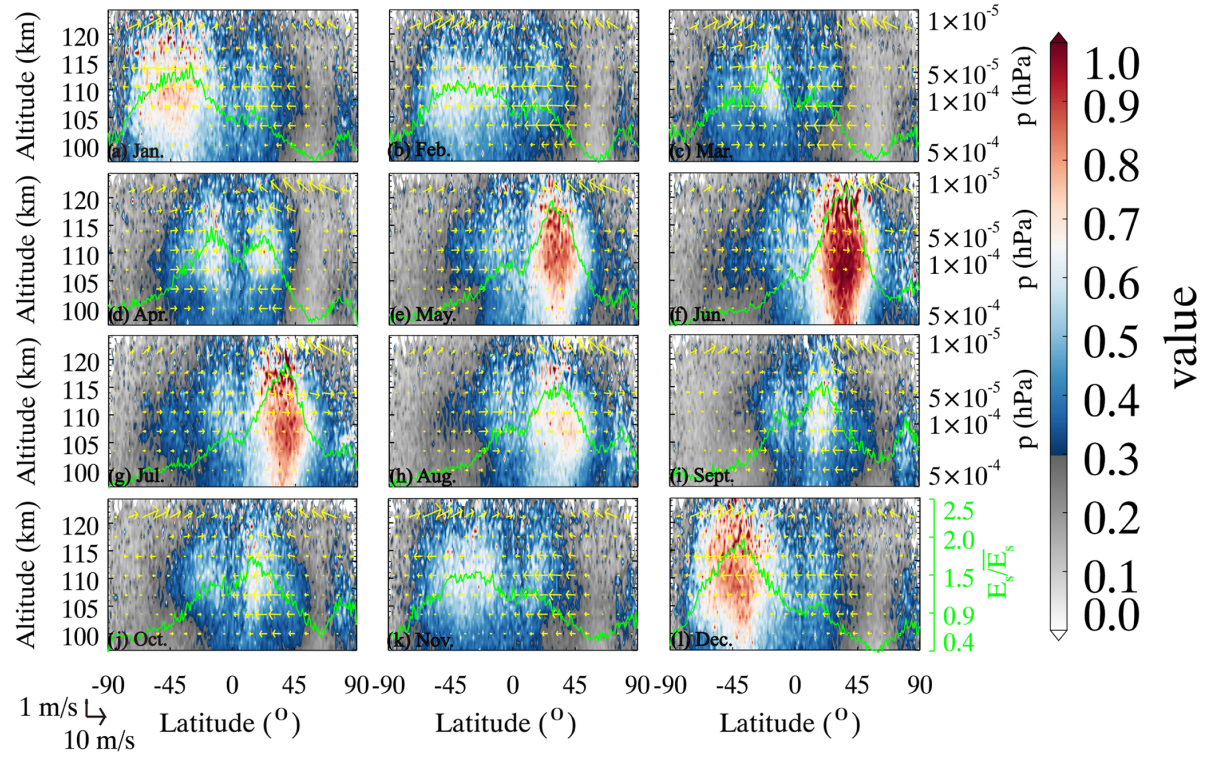

Figure 3. Monthly variation in the $E_{\mathrm{S}}$ layer intensity represented by the S4max index from COSMIC, with superposed ion drifts from the model caused by residual meridional circulations. The monthly mean variations in $E_{\mathrm{S}}$ layers are shown for different altitudes and latitudes from 2006 to 2011. The solid green lines are the ratios of column densities at different latitudes to the global mean column density. The yellow arrows between altitudes of $100-120 \mathrm{~km}$ show the predicted vertical and meridional velocity of ion drift (vectors with a scale of $\left.1 \mathrm{~m} \cdot \mathrm{s}^{-1} / 10 \mathrm{~m} \cdot \mathrm{s}^{-1}\right)$, driven by the atmospheric meridional circulations from the SD-WACCM4.

et al., 1984; Bristow and Watkins, 1991; Bedey and Watkins, 2001; Huba et al., 2019; Kirkwood and Nilsson, 2000). A global atmospheric model of meteoric iron (WACCM-Fe) (Feng et al., 2013) reproduces the global seasonal variations of $\mathrm{Fe}^{+}$density over the altitude range of $E_{\mathrm{s}}$ layers. The $\boldsymbol{E} \times \boldsymbol{B}$ drift and Coulomb force-induced ion drift (Cai et al., 2019) associated with the electric field are derived from standard WACCM X (Liu et al., 2018), and the seasonal variation of global distribution of $\mathrm{Fe}^{+}$is from WACCM Fe (Feng et al., 2013). Figure 4 shows the monthly mean $\mathrm{Fe}^{+}$flux $\Phi_{\mathrm{Fe}^{+}}$, calculated offline from WACCM X and WACCM Fe. The corresponding latitude-height plots and maps of $\mathrm{Fe}^{+}$flux due to $\boldsymbol{E} \times \boldsymbol{B}$ drift, Coulomb force-induced ion drift, and neutral winds in January and July are shown in Fig. $4 a-b$ and c-d. The colour scale denotes the meridional $\mathrm{Fe}^{+}$flux and extends from -1 (southward) to +1 (northward). This clearly shows a convergence of $\mathrm{Fe}^{+}$flux between 105 and $115 \mathrm{~km}$ at $25-45^{\circ} \mathrm{S}$ in winter and $25-45^{\circ} \mathrm{N}$ in summer. The horizontal red lines in Fig. 4a and c represent the altitude of $106 \mathrm{~km}$ at which the peak density of $E_{\mathrm{S}}$ layers reaches its maximum value and the lower thermospheric meridional circulation dominates. Figure $4 \mathrm{~b}$ and $\mathrm{d}$ show the $\mathrm{Fe}^{+}$flux at this height as a function of latitude and longitude. The $\mathrm{Fe}^{+}$meridional flux is mostly southward in winter (typically $-3.3 \times 10^{7}$ to $-2.3 \times 10^{9} \mathrm{~m}^{-2} \mathrm{~s}^{-1}$ ) and northward in summer (typically $1.6 \times 10^{7}$ to $4.9 \times 10^{9} \mathrm{~m}^{-2} \mathrm{~s}^{-1}$ ).

Although a variety of ground-based measurements have been performed, most studies interpret observations of earth metallic species in vertical and small-scale transport pro- cesses (Macleod, 1966; Plane, 2003; Davis and Johnson, 2005; Johnson and Davis, 2006; Davis and Lo, 2008; Haldoupis, 2012; Chu et al., 2014; Yu et al., 2015; Cai et al., 2017; Yu et al., 2017, 2019a). It is especially important to further monitor the ion-drift motions generated by meridional flows. Signatures in $E_{\mathrm{s}}$ seasonal variations by ion interhemispheric transport were investigated using the two meridional chains of low-latitude to mid-latitude ionosonde stations as shown in Fig. 5a. Figure 5b-c show the long-term time series of $E_{\mathrm{S}}$ layers at each station. The daily mean intensities of $E_{\mathrm{S}}$ layers, found by taking a monthly moving average, are plotted using red to blue colours, corresponding to the lowlatitude to mid-latitude stations. Specifically, all 10 stations exhibit a strong summer peak, which appears earlier at the low-latitude stations than at the mid-latitude stations. This trend can be used to quantitatively estimate the ion velocity of winter-to-summer interhemispheric transport.

In Fig. 6, green and red points represent annual summer peaks for 10 stations from two meridional chains. Each point represents a day of year (DOY) of the $E_{\mathrm{S}}$ summer maximum. The mean DOY for summer peaks is shown as a box, with the error bar representing the standard error in this mean. An estimation of ion meridional transport was made from the variations in peak time with latitude. Linear fits are presented using measurements from the Greenwich meridional chain (green line), $120^{\circ} \mathrm{E}$ longitudinal chain (red line), and a total of 10 stations (blue line). A linear correlation is found in the Greenwich meridional chain (correlation coefficient: $r=0.38$ ). The $p$ value is 0.53 calculated for testing 
(a) $\mathrm{Fe}^{+}$Ion Flux (WACCM Fe model, January)

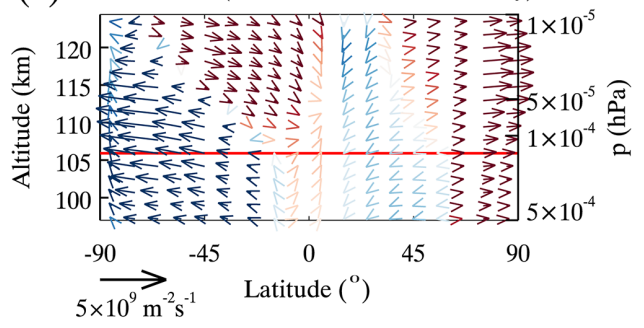

(b)

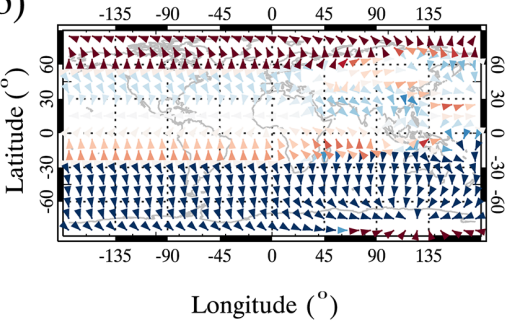

(c) $\mathrm{Fe}^{+}$Ion Flux (WACCM Fe model, July)

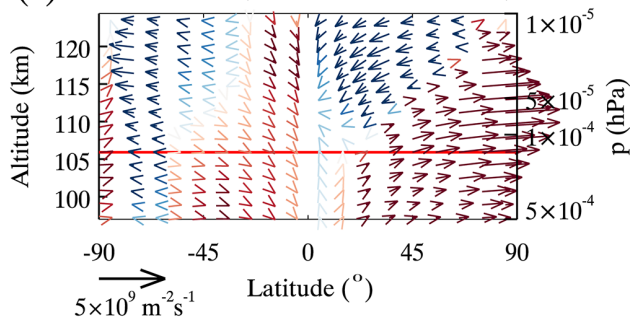

(d)

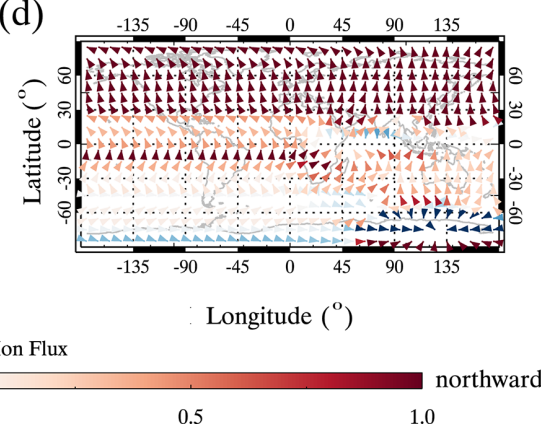

Figure 4. (a) Zonal mean latitude-height plot of $\mathrm{Fe}^{+}$flux $\Phi_{\mathrm{Fe}^{+}}\left(\mathrm{m}^{-2} \mathrm{~s}^{-1}\right)$ calculated offline from WACCM X and WACCM Fe in January, adding $\boldsymbol{E} \times \boldsymbol{B}$ drift, Coulomb force-induced ion drift, and neutral wind effects. The colour scale denotes the meridional $\mathrm{Fe}^{+}$flux and extends from -1 (southward) to +1 (northward). Also plotted are ion flux vectors that combine the meridional $\mathrm{Fe}^{+}$flux with the vertical Fe $^{+}$flux. The horizontal red line represents the altitude of $106 \mathrm{~km}$ at which the peak density of $E_{\mathrm{S}}$ layer reaches its maximum value. (b) Map of Fe ${ }^{+}$ flux at an altitude of $106 \mathrm{~km}$ from the model in January. Panels (c) and (d) show a zonal mean latitude-height plot and map of Fe ${ }^{+}$flux, respectively, from the model in July.

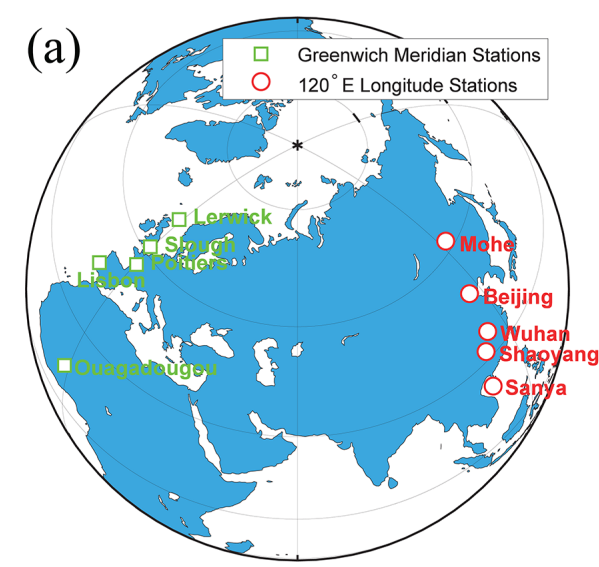

(b)

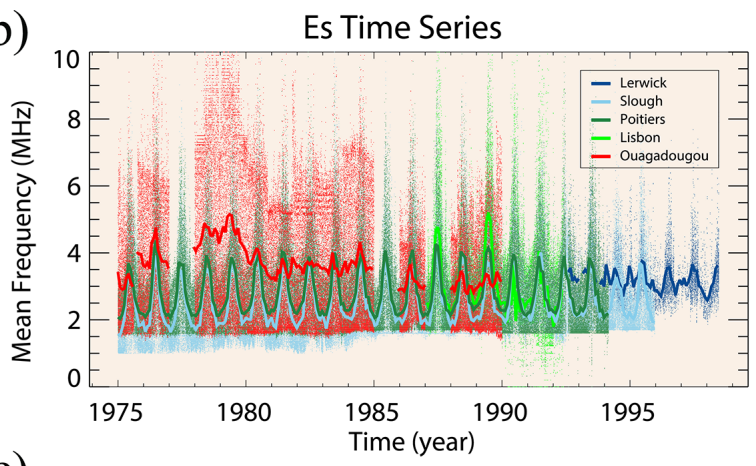

(c)

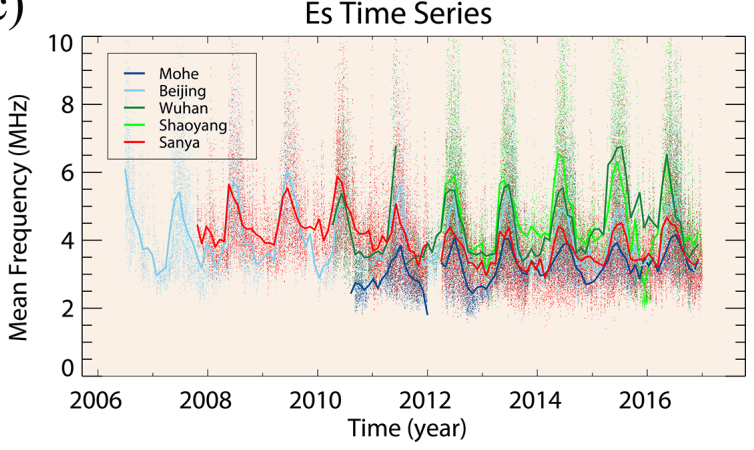

Figure 5. (a) Ground-based measurements of $E_{\mathrm{S}}$ from two meridional chains of low-latitude to mid-latitude ionosondes. There are 10 ionosonde stations in these two meridional chains, roughly along the Greenwich meridian (b) and $120^{\circ} \mathrm{E}$ (c). These ionospheric observations started in 1975. A 35-year dataset is analysed to try to identify the signature of the large-scale horizontal transport of metallic ions in $E_{\mathrm{S}}$, induced by meridional circulations. 


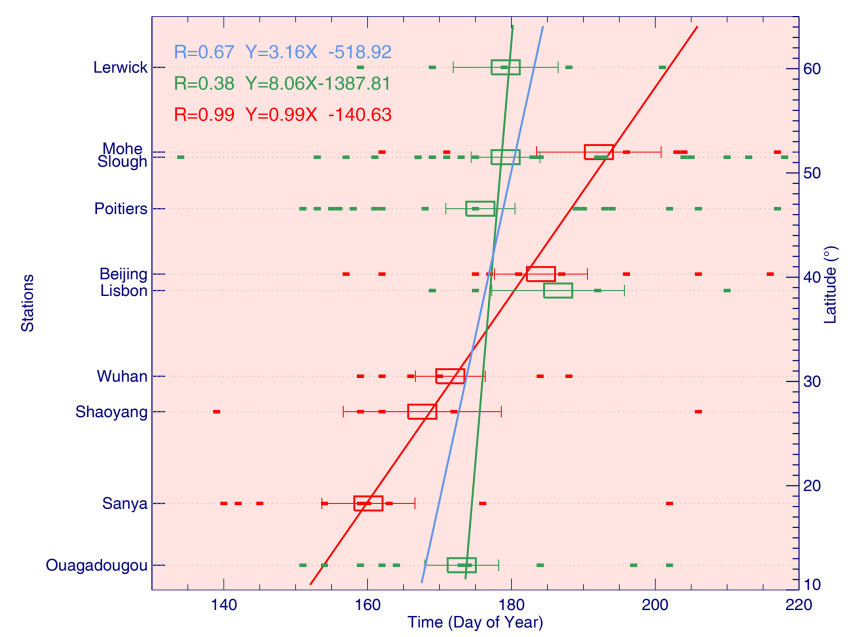

Figure 6. Latitudes of stations versus the mean day-of-year (DOY) time of the annual summer peaks for 10 stations from two meridional chains during 1975-2016. The ionosonde stations cover 10$60^{\circ} \mathrm{N}$. Green and red points are the annual summer peaks, and each point represents a DOY of a $E_{\mathrm{S}}$ summer peak. The mean DOY time of summer peaks is shown as a box, with the error bar representing the standard error in this mean for each station. The green, red, and blue lines show the linear fits between the peak time and latitude, using measurements from the Greenwich meridional chain, $120^{\circ} \mathrm{E}$ longitudinal chain, and the total of all 10 stations, respectively. The linear fit relationship and correlation coefficient are also given, from which an ion meridional velocity in a meridional chain could be quantitatively estimated.

the hypothesis of no correlation. The slope is $8.06 \pm 0.15^{\circ} / \mathrm{d}$ $(10.35 \pm 0.19 \mathrm{~m} / \mathrm{s})$, indicating winter-to-summer ion transport. This value is slightly larger than the predicted meridional velocity in Fig. $3 ;-1.08-7.45 \mathrm{~m} / \mathrm{s}$ between $10-60^{\circ} \mathrm{N}$ in summer. The slope from the $120^{\circ} \mathrm{E}$ longitudinal chain is $0.99 \pm 0.29^{\circ} / \mathrm{d} \sim 1.27 \pm 0.37 \mathrm{~m} / \mathrm{s}(r=0.99, p<0.01)$, which is within the predicted range of ion meridional velocity. This velocity is lower than that from the Greenwich meridional chain, and this is thought to be due to the differences in the magnitude of meridional flows between different solar cycles. The blue line represents the fit for all 10 stations $(r=0.67, p=0.04)$. The estimated ion meridional velocity is $3.16 \pm 0.13^{\circ} / \mathrm{d}(4.06 \pm 0.17 \mathrm{~m} / \mathrm{s})$. In modelling studies, the dynamics of the lower thermospheric meridional circulation are much less understood than the well-known mesospheric meridional circulation (Liu, 2007; Qian et al., 2017; Qian and Yue, 2017). It is difficult to directly measure the mean meridional wind since the lower thermospheric meridional circulation is considerably smaller than the tidal amplitudes $(\mathrm{Wu}$ et al., 2008). The results presented here show that the atmospheric circulation has a marked influence on the meridional transport and seasonal variations of the metallic ions in $E_{\mathrm{S}}$ layers. There is also some evidence that the magnitude of the meridional flows may vary with longitude.

\section{Conclusions}

The lower thermospheric winter-to-summer meridional circulation is a process that has generally been ignored, although it plays a fundamental role, comparable to the vertical wind shear, in the transport of metallic ions throughout the Earth's upper atmosphere and ionosphere. Two differences should be noted though, i.e. the distribution of metallic ions and the formation of the $E_{\mathrm{s}}$. The former is determined by the transport, as demonstrated here in this study, while the latter is probably directly tied to shear. The large-scale horizontal transport of metallic ions needs to be considered over seasonal-to-interannual timescales in global-scale studies of metallic species, and this provides a mechanism that explains the observed $E_{\mathrm{S}}$ seasonal variations (Whitehead, 1960). In addition to the interhemispheric transport, a comprehensive explanation for $E_{\mathrm{s}}$ production requires the use of a whole atmosphere climate model, including all the necessary chemistry and electrodynamics of metallic species. Global models of meteoric metals in the upper atmosphere have been developed by adding the metal chemistry into WACCM (Marsh et al., 2013; Feng et al., 2013; Wu et al., 2019). The results presented here provide an important dynamical constraint for modelling studies that aim to simulate the variations in composition of the thermosphere and ionosphere on seasonal and interannual timescales. 


\section{Appendix A: Methods}

\section{A1 Satellite and ground-based observations}

The COSMIC multi-satellite dataset was used to investigate the global morphology of $E_{\mathrm{S}}$ layers during the period 20062011. For this we used the COSMIC-GPS amplitude scintillation index S4 (Yu et al., 2020), including the maximum S4 index (S4max), as well as the latitude, longitude, altitude, and time at which $\mathrm{S} 4 \mathrm{max}$ was detected.

The long-term ground-based observations of intensities of $E_{\mathrm{s}}$ layers represented by the critical frequencies $f_{\mathrm{o}} E_{\mathrm{s}}$ from two meridional chains of low-latitude to mid-latitude ionosonde stations were used in this study. These are five ionospheric sounders (ionosondes) located roughly along the Greenwich meridian $\left(0^{\circ} \mathrm{E}\right)$ at Lerwick $\left(60.13^{\circ} \mathrm{N}, 1.18^{\circ} \mathrm{W}\right)$, Slough $\left(51.51^{\circ} \mathrm{N}, 0.60^{\circ} \mathrm{W}\right)$, Poitiers $\left(46.57^{\circ} \mathrm{N}, 0.35^{\circ} \mathrm{E}\right)$, Lisbon $\left(38.72^{\circ} \mathrm{N}, 9.27^{\circ} \mathrm{W}\right)$, and Ouagadougou $\left(12.37^{\circ} \mathrm{N}\right.$, $1.53^{\circ} \mathrm{W}$ ) between 1975 and 1998 and five digital ionosondes (digisondes) (Bibl and Reinisch, 1978) located roughly along $120^{\circ} \mathrm{E}$ longitude at Mohe $\left(52.0^{\circ} \mathrm{N}, 122.5^{\circ} \mathrm{E}\right)$, Beijing $\left(40.3^{\circ} \mathrm{N}, 116.2^{\circ} \mathrm{E}\right)$, Wuhan $\left(30.5^{\circ} \mathrm{N}, 114.4^{\circ} \mathrm{E}\right)$, Shaoyang $\left(27.1^{\circ} \mathrm{N}, 111.3^{\circ} \mathrm{E}\right)$, and Sanya $\left(18.3^{\circ} \mathrm{N}, 109.4^{\circ} \mathrm{E}\right)$ between 2006 and 2016 under the Chinese Meridian Project (Wang, 2010).

\section{A2 Atmospheric meridional circulations and three-dimensional wind shear theory}

The atmospheric meridional circulations are calculated using the Whole Atmosphere Community Climate Model (WACCM). These circulations are the summer-to-winter mesospheric circulation, the winter-to-summer lower thermospheric circulation, and the summer-to-winter circulation. WACCM is a global climate model with interactive chemistry, developed at the National Center for Atmospheric Research. A specified dynamics version of WACCM4 (SDWACCM4) (Marsh et al., 2013) is used. SD-WACCM4 is constrained by relaxing the temperature and horizontal winds to those from the Modern-Era Retrospective Analysis for Research and Applications, which is a NASA reanalysis for the satellite era by a major new version of the Goddard Earth Observing System Data Assimilation System Version 5 (Rienecker et al., 2011).

It is widely accepted that the mechanism for $E_{\mathrm{s}}$ formation at mid-latitudes is wind shear. From the vertical wind shear theory (Mathews, 1998), the vertical motion of metallic ions by the neutral winds is described by Eq. (A1):

$$
w_{\mathrm{i}}=\frac{r_{\mathrm{i}} \cos I}{1+r_{\mathrm{i}}^{2}} \times U-\frac{\sin I \cos I}{1+r_{\mathrm{i}}^{2}} \times V+\frac{r_{\mathrm{i}}^{2}+\sin ^{2} I}{1+r_{\mathrm{i}}^{2}} \times W,
$$

where $w_{\mathrm{i}}$ represents the vertical velocity of ions; $I$ represents the dip angle of the geomagnetic field $\boldsymbol{B}$ (positive in the downward direction in the Northern Hemisphere); $r_{\mathrm{i}}$ is the ratio of the ion-neutral collision frequency $\left(v_{\mathrm{i}}\right)$ to the ion gyrofrequency $\left(\omega_{\mathrm{i}}\right)$; and $\boldsymbol{V}_{\mathrm{n}}(U, V, W)$ represents the neutral wind in zonal (positive for eastward), meridional (positive for northward), and vertical (positive for upward).

From Eq. (A1), which describes the classical wind shear theory, the zonal and meridional winds act upon the vertical plasma convergence of metallic ions at all altitudes, as weighted by the ratio $r_{\mathrm{i}}$ of $v_{\mathrm{i}}$ to $\omega_{\mathrm{i}}$. However, the meridional component of ion velocity should also be included in the wind shear theory. The formation of an $E_{\mathrm{S}}$ layer is controlled fully by the ion dynamics and expressed through a basic ion momentum equation (Chimonas and Axford, 1968) (Eq. A2 below). The steady-state ion momentum equation includes the ion-neutral collision and geomagnetic Lorentz forces:

$m_{\mathrm{i}} \frac{\mathrm{d} \boldsymbol{v}_{\mathrm{i}}}{\mathrm{d} t}=0=e\left(\boldsymbol{E}+\boldsymbol{v}_{\mathrm{i}} \times \boldsymbol{B}\right)-m_{\mathrm{i}} v_{\mathrm{i}}\left(\boldsymbol{v}_{\mathrm{i}}-\boldsymbol{V}_{\mathrm{n}}\right)$,

where $m_{\mathrm{i}}$ is the ion mass, $\boldsymbol{B}(B \sin D \cos I, B \cos D \cos I$, $-B \sin I)$ is the magnetic field, $I$ and $D$ are the dip angle and declination angle of the magnetic field, $\boldsymbol{v}_{\mathrm{i}}\left(u_{\mathrm{i}}, v_{\mathrm{i}}, w_{\mathrm{i}}\right)$ is the ion drift velocity, and $V_{\mathrm{n}}(U, V, W)$ is the neutral wind. We derive the ion drift in the zonal, meridional, and vertical directions from Eq. (A2) by adopting an east, north, and vertically upward Cartesian coordinate system, respectively. When the electric filed $\boldsymbol{E}$ is neglected, a conventional presentation of the wind shear theory is derived. As the vertical wind shear is described in the vertical component, we refer to this extended view of the formation and transport of the layering process as "generalized wind shear theory" with threedimensional motions of ion drift:

$$
\begin{aligned}
u_{\mathrm{i}} & =\frac{r_{\mathrm{i}}^{2}+\sin ^{2} D \cos ^{2} I}{1+r_{\mathrm{i}}^{2}} U+\frac{-r_{\mathrm{i}} \sin I+\sin D \cos D \cos ^{2} I}{1+r_{\mathrm{i}}^{2}} V \\
& -\frac{r_{\mathrm{i}} \cos D \cos I+\sin D \sin I \cos I}{1+r_{\mathrm{i}}^{2}} W, \\
v_{\mathrm{i}} & =\frac{r_{\mathrm{i}} \sin I+\sin D \cos D \cos ^{2} I}{1+r_{\mathrm{i}}^{2}} U+\frac{r_{\mathrm{i}}^{2}+\cos ^{2} D \cos ^{2} I}{1+r_{\mathrm{i}}^{2}} V \\
& +\frac{r_{\mathrm{i}} \sin D \cos I-\cos D \sin I \cos I}{1+r_{\mathrm{i}}^{2}} W, \\
w_{\mathrm{i}} & =\frac{r_{\mathrm{i}} \cos D \cos I-\sin D \sin I \cos I}{1+r_{\mathrm{i}}^{2}} U \\
& -\frac{r_{\mathrm{i}} \sin D \cos I+\cos D \sin I \cos I}{1+r_{\mathrm{i}}^{2}} V+\frac{r_{\mathrm{i}}^{2}+\sin ^{2} I}{1+r_{\mathrm{i}}^{2}} W .
\end{aligned}
$$

The contributions to meridional and vertical ion drift from $U$, $V$, and $W$ in January and July are shown separately in Fig. 1. Both $U$ and $V$ are the main contributors to vertical ion velocity. The ion dynamics become collision dominated $\left(r_{\mathrm{i}} \gg 1\right)$ below $125 \mathrm{~km}$ altitude (Mathews, 1998). Therefore, the $U$ term on the right of Eq. (A5) is more important than the $V$ term, representing the relative dominant role of $U$ in comparison with $V$ in the vertical motion of ions. The second term with $V$ of Eq. (A4) is more important than the other terms, 
representing the dominant $V$ contribution to the meridional velocity of ions. 
Code and data availability. The COSMIC S4max data are available from the CDAAC website (https://data.cosmic.ucar.edu/ gnss-ro/, CDAAC, 2021). The ionosonde data are available from the Data Centre for Meridian Space Weather Monitoring Project (https://data.meridianproject.ac.cn/data-directory/, Meridian Space Weather Monitoring Project, 2021); Geophysics Center, National Earth System Science Data Center at BNOSE, IGGCAS (http: //wdc.geophys.ac.cn/dbView.asp?IonoPublish, BNOSE, IGGCAS, 2021); and the UKSSDC at the Rutherford Appleton Laboratory (https://www.ukssdc.ac.uk/wdcc1/iono_menu.html, UKSSDC, 2021). WACCM is an open-source community model available at the NCAR website (https://www.cesm.ucar.edu/models/cesm2/, UCAR, 2021). The model datasets used in this study are also freely available from National Space Science Data Center, National Science \& Technology Infrastructure of China (https://doi.org/10. 12176/01.99.00256, Yu et al., 2021b).

Author contributions. BY, XX, and CJS designed the study and wrote the manuscript. JW performed the WACCM model runs. WF, DRM, HL, and JMCP contributed to the discussion and explanation of model simulations. XY provided the COSMIC radio occultation data and contributed significantly to the comments on an early version of the manuscript. YC and XD contributed to the discussion of the results and the preparation of the manuscript. All authors discussed the results and commented on the manuscript at all stages.

Competing interests. The authors declare that they have no conflict of interest.

Acknowledgements. We acknowledge the Constellation Observing System for Meteorology, Ionosphere, and Climate (COSMIC) Data Analysis and Archive Center (CDAAC) for providing COSMIC radio occultation data, the ionospheric data from the UK Solar System Data Centre (UKSSDC) at the Rutherford Appleton Laboratory, the Chinese Meridian Project, the Solar-Terrestrial Environment Research Network (STERN), and the Geophysics Center, National Earth System Science Data Center at BNOSE, IGGCAS. The numerical calculations in this paper have been done on the supercomputing system at the Supercomputing Center of the University of Science and Technology of China. The authors would like to thank the National Science \& Technology Infrastructure of China.

Financial support. This work has been supported by the B-type Strategic Priority Program of CAS (grant no. XDB41000000), the National Natural Science Foundation of China (grant nos. 41774158, 41974174, 41831071, 42074181), Anhui Provincial Natural Science Foundation (grant no. 1908085QD155), the Joint Open Fund of Mengcheng National Geophysical Observatory (grant no. MENGO-202008), and the Fundamental Research Fund for the Central Universities. Wuhu Feng and John M. C. Plane were supported by the Natural Environment Research Council (grant no. NE/P001815/1). Bingkun Yu was supported by the Royal Society for the Newton International Fellowship (grant no. $\mathrm{NIF} \backslash \mathrm{R} 1 \backslash 180815)$.
Review statement. This paper was edited by Ken Carslaw and reviewed by two anonymous referees.

\section{References}

Anthes, R. A., Bernhardt, P. A., Chen, Y., Cucurull, L., Dymond, K. F., Ector, D., Healy, S. B., Ho, S.-P., Hunt, D. C., Kuo, Y.-H., Liu, H., Manning, K., McCormick, C., Meehan, T. K., Randel, W. J., Rocken, C., Schreiner, W. S., Sokolovskiy, S. V., Syndergaard, S., Thompson, D. C., Trenberth, K. E., Wee, T.-K., Yen, N. L., and Zeng, Z.: The COSMIC/FORMOSAT-3 mission: Early results, B. Am. Meteor. Soc., 89, 313-334, 2008.

Arras, C. and Wickert, J.: Estimation of ionospheric sporadic $E$ intensities from GPS radio occultation measurements, J. Atmos. Sol.-Terr. Phys., 171, 60-63, 2018.

Arras, C., Wickert, J., Beyerle, G., Heise, S., Schmidt, T., and Jacobi, C.: A global climatology of ionospheric irregularities derived from GPS radio occultation, Geophys. Res. Lett., 35, L14809, https://doi.org/10.1029/2008GL034158, 2008.

Bedey, D. F. and Watkins, B. J.: Simultaneous observations of thin ion layers and the ionospheric electric field over Sondrestrom, J. Geophys. Res.-Space, 106, 8169-8183, 2001.

Bibl, K. and Reinisch, B. W.: The universal digital ionosonde, Radio Science, 13, 519-530, 1978.

BNOSE, IGGCAS: Ionosonde data, available at: http://wdc. geophys.ac.cn/dbView.asp?IonoPublish, last access: 1 January 2021.

Bristow, W. and Watkins, B.: Numerical simulation of the formation of thin ionization layers at high latitudes, Geophys. Res. Lett., 18, 404-407, 1991.

Cai, X., Yuan, T., and Eccles, J. V.: A numerical investigation on tidal and gravity wave contributions to the summer time Na variations in the midlatitude E region, J. Geophys. Res.-Space, 122, 10577-10595, https://doi.org/10.1002/2016JA023764, 2017.

Cai, X., Yuan, T., Eccles, J. V., Pedatella, N., Xi, X., Ban, C., and Liu, A. Z.: A Numerical Investigation on the Variation of Sodium ion and observed Thermospheric Sodium Layer at Cerro Pachón, Chile during Equinox, J. Geophys. Res.-Space, 124, 10395-10414, https://doi.org/10.1029/2018JA025927, 2019.

CDAAC: COSMIC RO data, available at: https://data.cosmic.ucar. edu/gnss-ro/, last access: 1 January 2021.

Chimonas, G. and Axford, W.: Vertical movement of temperatezone sporadic E layers, J. Geophys. Res., 73, 111-117, 1968.

Chu, Y.-H., Wang, C., Wu, K., Chen, K., Tzeng, K., Su, C.-L., Feng, W., and Plane, J.: Morphology of sporadic $E$ layer retrieved from COSMIC GPS radio occultation measurements: Wind shear theory examination, J. Geophys. Res.-Space, 119, 2117-2136, 2014.

Collinson, G. A., McFadden, J., Grebowsky, J., Mitchell, D., Lillis, R., Withers, P., Vogt, M. F., Benna, M., Espley, J., and Jakosky, B.: Constantly forming sporadic $E$-like layers and rifts in the Martian ionosphere and their implications for Earth, Nat. Astron., 4, 486-491, 2020.

Davis, C. J. and Johnson, C.: Lightning-induced intensification of the ionospheric sporadic $E$ layer, Nature, 435, 799-801, 2005.

Davis, C. J. and Lo, K.-H.: An enhancement of the ionospheric sporadic- $E$ layer in response to negative polarity cloud-toground lightning, Geophys. Res. Lett., 35, L05815, 2008. 
Feng, W., Marsh, D. R., Chipperfield, M. P., Janches, D., Höffner, J., Yi, F., and Plane, J. M.: A global atmospheric model of meteoric iron, J. Geophys. Res.-Atmos., 118, 9456-9474, 2013.

Grebowsky, J. M. and Aiken, A. C.: In situ measurements of meteoric ions, in Meteors in the Earth's Atmosphere, Cambridge Univ. Press, Cambridge, UK, 2002.

Haldoupis, C.: Midlatitude sporadic E. A typical paradigm of atmosphere-ionosphere coupling, Space Sci. Rev., 168, 441-461, 2012.

Haldoupis, C., Pancheva, D., Singer, W., Meek, C., and MacDougall, J.: An explanation for the seasonal dependence of midlatitude sporadic E layers, J. Geophys. Res.-Space, 112, A06315, https://doi.org/10.1029/2007JA012322, 2007.

Huba, J., Krall, J., and Drob, D.: Global Ionospheric Metal Ion Transport With SAMI3, Geophys. Res. Lett., 46, 7937-7944, 2019

Johnson, C. and Davis, C. J.: The location of lightning affecting the ionospheric sporadic- $E$ layer as evidence for multiple enhancement mechanisms, Geophys. Res. Lett., 33, L07811, https://doi.org/10.1029/2005GL025294, 2006.

Kirkwood, S. and Nilsson, H.: High-latitude sporadic- $E$ and other thin layers-the role of magnetospheric electric fields, Space Sci. Rev., 91, 579-613, 2000.

Kopp, E.: On the abundance of metal ions in the lower ionosphere, J. Geophys. Res.-Space, 102, 9667-9674, 1997.

Layzer, D.: Theory of midlatitude sporadic E, Radio Sci., 7, 385395, 1972.

Liu, H.-L.: On the large wind shear and fast meridional transport above the mesopause, Geophys. Res. Lett., 34, L08815, https://doi.org/10.1029/2006GL028789, 2007.

Liu, H.-L., Bardeen, C. G., Foster, B. T., Lauritzen, P., Liu, J., Lu, G., Marsh, D. R., Maute, A., McInerney, J. M., Pedatella, N. M., Qian, L., Richmond, A. D., Roble, R. G., Solomon, S. C., Vitt, F. M., and Wang, W.: Development and validation of the Whole Atmosphere Community Climate Model with thermosphere and ionosphere extension (WACCM-X 2.0), J. Adv. Model. Earth Sy., 10, 381-402, 2018.

Macleod, M. A.: Sporadic $E$ theory. I. Collision-geomagnetic equilibrium, J. Atmos. Sci., 23, 96-109, 1966.

Marsh, D. R., Mills, M. J., Kinnison, D. E., Lamarque, J.-F., Calvo, N., and Polvani, L. M.: Climate change from 1850 to 2005 simulated in CESM1 (WACCM), J. Climate, 26, 7372-7391, 2013.

Mathews, J. D.: Sporadic E: current views and recent progress, J. Atmos. Sol.-Terr. Phys., 60, 413-435, 1998.

Meridian Space Weather Monitoring Project: Ionosonde data, available at: https://data.meridianproject.ac.cn/data-directory/, last access: 1 January 2021.

Nygren, T., Jalonen, L., Oksman, J., and Turunen, T.: The role of electric field and neutral wind direction in the formation of sporadic E-layers, J. Atmos. Sol.-Terr. Phys., 46, 373-381, 1984.

Plane, J. M.: Atmospheric chemistry of meteoric metals, Chem. Rev., 103, 4963-4984, https://doi.org/10.1021/cr0205309, 2003.

Plane, J. M., Feng, W., and Dawkins, E. C.: The mesosphere and metals: Chemistry and changes, Chem. Rev., 115, 4497-4541, 2015.

Qian, L. and Yue, J.: Impact of the lower thermospheric winter-tosummer residual circulation on thermospheric composition, Geophys. Res. Lett., 44, 3971-3979, 2017.
Qian, L., Burns, A., and Yue, J.: Evidence of the lower thermospheric winter-to-summer circulation from SABER $\mathrm{CO}_{2}$ observations, Geophys. Res. Lett., 44, 10100-10107, 2017.

Resende, L. C. A., Arras, C., Batista, I. S., Denardini, C. M., Bertollotto, T. O., and Moro, J.: Study of sporadic E layers based on GPS radio occultation measurements and digisonde data over the Brazilian region, Ann. Geophys., 36, 587-593, https://doi.org/10.5194/angeo-36-587-2018, 2018.

Rienecker, M. M., Suarez, M. J., Gelaro, R., Todling, R., Bacmeister, J., Liu, E., Bosilovich, M. G., Schubert, S. D., Takacs, L., Kim, G.-K., Bloom, S., Chen, J., Collins, D., Conaty, A., da Silva, A., Gu, W., Joiner, J., Koster, R. D., Lucchesi, R., Molod, A., Owens, T., Pawson, S., Pegion, P., Redder, C. R., Reichle, R., Robertson, F. R., Ruddick, A. G., Sienkiewicz, M., and Woollen, J.: MERRA: NASA's modern-era retrospective analysis for research and applications, J. Climate, 24, 3624-3648, 2011.

Smith, A. K., Garcia, R. R., Marsh, D. R., and Richter, J. H.: WACCM simulations of the mean circulation and trace species transport in the winter mesosphere, J. Geophys. Res.-Atmos., 116, D20115, https://doi.org/10.1029/2011JD016083, 2011.

Smith, E.: Some unexplained features in the statistics for intense sporadic $E$, Second Seminar on the cause and structure of temperate latitude sporadic-E, Vail, Colorado, 19-22 June 1968, paper 12, 1968.

Tsai, L.-C., Su, S.-Y., Liu, C.-H., Schuh, H., Wickert, J., and Alizadeh, M. M.: Global morphology of ionospheric sporadic $E$ layer from the FormoSat-3/COSMIC GPS radio occultation experiment, GPS Solut., 22, 118, https://doi.org/10.1007/s10291018-0782-2, 2018.

UCAR: WACCM model, available at: https://www.cesm.ucar.edu/ models/cesm2/, 1 January 2021.

UK Solar System Data Centre (UKSSDC): Ionosonde data, available at: https://www.ukssdc.ac.uk/wdcc1/iono_menu.html, last access: 1 January 2021.

Wang, C.: New chains of space weather monitoring stations in China, Adv. Space Res., 8, S08001, https://doi.org/10.1029/2010SW000603, 2010.

Whitehead, J.: Formation of the sporadic $E$ layer in the temperate zones, Nature, 188, 567, https://doi.org/10.1038/188567a0, 1960.

Whitehead, J.: Recent work on mid-latitude and equatorial sporadic-E, J. Atmos. Terr. Phys., 51, 401-424, 1989.

Wu, D. L., Ao, C. O., Hajj, G. A., de La Torre Juarez, M., and Mannucci, A. J.: Sporadic $E$ morphology from GPS-CHAMP radio occultation, J. Geophys. Res.-Space, 110, A01306, https://doi.org/10.1029/2004JA010701, 2005.

Wu, J., Feng, W., Xue, X., Marsh, D., Plane, J., and Dou, X.: The 27-day solar rotational cycle response in the mesospheric metal layers at low latitudes, Geophys. Res. Lett., 46, 71997206, https://doi.org/10.1029/2019GL083888, 2019.

Wu, Q., Ortland, D., Killeen, T. L., Roble, R., Hagan, M., Liu, H.-L., Solomon, S., Xu, J., Skinner, W., and Niciejewski, R.: Global distribution and interannual variations of mesospheric and lower thermospheric neutral wind diurnal tide: 1. Migrating tide, J. Geophys. Res.-Space, 113, A05308, https://doi.org/10.1029/2007JA012542, 2008.

Yu, B., Xue, X., Lu, G., Ma, M., Dou, X., Qie, X., Ning, B., Hu, L., Wu, J., and Chi, Y.: Evidence for lightning-associated enhance- 
ment of the ionospheric sporadic E layer dependent on lightning stroke energy, J. Geophys. Res.-Space, 120, 9202-9212, 2015.

Yu, B., Xue, X., Lu, G., Kuo, C.-L., Dou, X., Gao, Q., Qie, X., Wu, J., Qiu, S., Chi, Y., and Tang, Y.: The enhancement of neutral metal Na layer above thunderstorms, Geophys. Res. Lett., 44, 9555-9563, 2017.

Yu, B., Xue, X., Kuo, C., Lu, G., Scott, C. J., Wu, J., Ma, J., Dou, X., Gao, Q., Ning, B., Hu, L., Wang, G., Jia, M., Yu, C., and Qie, X.: The intensification of metallic layered phenomena above thunderstorms through the modulation of atmospheric tides, Sci. Rep.-UK, 9, 1-13, 2019a.

Yu, B., Xue, X., Yue, X., Yang, C., Yu, C., Dou, X., Ning, B., and $\mathrm{Hu}, \mathrm{L} .:$ The global climatology of the intensity of the ionospheric sporadic E layer, Atmos. Chem. Phys., 19, 4139-4151, https://doi.org/10.5194/acp-19-4139-2019, 2019b.

Yu, B., Scott, C. J., Xue, X., Yue, X., and Dou, X.: Derivation of global ionospheric sporadic E critical frequency ( $f_{o}$ Es) data from the amplitude variations in GPS/GNSS radio occultations, Roy. Soc. Open Sci., 7, 200320, https://doi.org/10.1098/rsos.200320, 2020.

Yu, B., Scott, C. J., Xue, X., Yue, X., and Dou, X.: Using GNSS radio occultation data to derive critical frequencies of the ionospheric sporadic E layer in real time. GPS Solut., 25, 14, https://doi.org/10.1007/s10291-020-01050-6, 2021a.
Yu, B., Xue, X., Scott, C. J., Wu, J., Yue, X., Feng, W., Chi, Y., Marsh, D. R., Liu, H., Dou, X., and Plane, J. M. C.: Simulation data of 'Interhemispheric transport of metallic ions within ionospheric sporadic E layers by the lower thermospheric meridional circulation', V1, NSSDC Space Science Article Data Repository, https://doi.org/10.12176/01.99.00256, 2021b.

Yuan, T., Wang, J., Cai, X., Sojka, J., Rice, D., Oberheide, J., and Criddle, N.: Investigation of the seasonal and local time variations of the high-altitude sporadic Na layer (Nas) formation and the associated midlatitude descending $E$ layer (Es) in lower $E$ region, J. Geophys. Res.-Space, 119, 5985-5999, 2014.

Yue, X., Schreiner, W. S., Zeng, Z., Kuo, Y.-H., and Xue, X.: Case study on complex sporadic $E$ layers observed by GPS radio occultations, Atmos. Meas. Tech., 8, 225-236, https://doi.org/10.5194/amt-8-225-2015, 2015.

Yue, X., Schreiner, W. S., Pedatella, N. M., and Kuo, Y.-H.: Characterizing GPS radio occultation loss of lock due to ionospheric weather, Adv. Space Res., 14, 285-299, 2016. 